\title{
Microstructural influence on tolerance to corrosion-induced damage in hardmetals
}

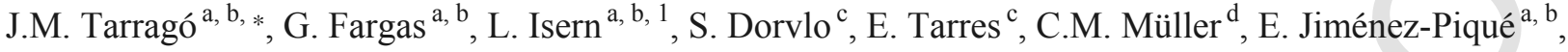 \\ L. Llanes ${ }^{\mathrm{a}, \mathrm{b}}$ \\ ${ }^{a}$ CIEFMA, Departament de Ciència dels Materials i Enginyeria Metal •lúrgica, Universitat Politècnica de Catalunya, EEBE, 08019 Barcelona, Spain \\ ${ }^{\mathrm{b}}$ CRnE, Centre de Recerca en Nanoenginyeria, Universitat Politècnica de Catalunya, 08019 Barcelona, Spain \\ c Sandvik Hyperion, Coventry CV4 OXG, UK \\ d ELECTRODEP, Departament de Química Física, Universitat de Barcelona, Martí i Franqués 1, 08028, Barcelona, Spain
}

\section{A R T I C L E IN F O}

\section{Article history:}

Received 6 April 2016

Received in revised form 22 August

2016

Accepted 24 August 2016

Available online $\mathrm{xxx}$

Keywords:

Cemented carbides

Cobalt

Corrosion

Fracture

3D FIB/FESEM tomography

\section{Abstract}

The influence of the microstructure on the tolerance of WC-Co cemented carbides to corrosion damage was studied by using residual strength as the critical design parameter. In doing so, samples were immersed in synthetic mine water solution for different times, and changes induced by corrosion exposure were assessed. A detailed 3D FIB/FESEM tomography characterization of corrosion damage-microstructure interactions is included. Results reveal that corrosion damage may result in relevant strength degradation on the basis of stress rising effects associated with the formation of surface corrosion pits. Thus, as immersion time increases strength gradually decreases. Fractographic examination reveals the formation of semi-elliptical and sharp corrosion pits for studied medium- and ultrafine-sized cemented carbides, respectively. The latter has a much more pronounced stress rising effect, and consequently higher strength losses were determined for ultrafine grades. Corrosion process consists of a selective attack of the binder that is dissolved in the corrosive media. Initially, it is located at centres of binder pools and as exposure time in the media increases, corrosion evolves consuming the rest of the pools which finally leaves an unsupported WC grain skeleton at the surface.

(C) 2016 Published by Elsevier Ltd.

\section{Introduction}

Cemented carbides, also referred to as hardmetals, are a group of ceramic-metal composite materials that exhibit an outstanding combination of hardness, wear resistance and toughness [1-3]. Their unique combination of properties has made of them the preferential choice in a large number of industrial applications demanding high performance under harsh working conditions, e.g. cutting and forming tools, mining bits and mechanical seals [4,5]. Hardmetals composite nature consists of hard and brittle ceramic particles (generally WC) embedded into a ductile metallic matrix forming two interpenetrating networks. The preferential choice for the ductile binder is Co but binders of different chemical nature (e.g. Ni, CoNi) are used in applications demanding enhanced performance under certain severe working conditions, such as corrosive environments and high temperatures [6].

Cemented carbides tools and components are frequently exposed to chemically aggressive media including a large variety of corrosive environments, such as lubricants, chemical and petrochemical products as well as mine- and sea- water (e.g. Refs. [7-10]). Therefore, it is of crucial importance to improve the corrosion resistance of cemented carbides in order to increase their service life and to prevent

\footnotetext{
* Corresponding author at: Sandvik Mining and Rock Technology AB, Västberga, Stockholm 126 79, Sweden.

Email address: jose.maria.tarrago@upc.edu, jose_maria.tarrago_cifre@sandvik. com (J.M. Tarragó)

${ }^{1}$ Current address: School of Aerospace, Transport and Manufacturing. Cranfield University, MK43 0AL Bedfordshire, UK.
}

premature failure of tools and components. In acidic and neutral $\mathrm{pH}$ solutions, hardmetals corrosion process consists on a galvanic couple where the binder is selectively attacked due to its anodic role [11-14], whereas WC particles are cathodically protected [13]. In addition, due to the larger surface area covered by ceramic particles, corrosion in the anodic sites gets enhanced [13]. The opposite trend is found in basic solutions, where ceramic particles dissolve and the binder phase passivates $[15,16]$. Corrosion mechanisms in cemented carbides are really complex and depend on a large number of factors such as surface state, corrosive medium, hardmetal microstructure and binder chemical nature. Furthermore, corrosion system is in constant evolution due to the continuous changes produced by the cathodic and anodic reactions taking place at the surface [13].

In-service performance of cemented carbides is not only dependent on their intrinsic mechanical properties but also is highly influenced by their resistance to the aggressive medium to which they are exposed. Within this context, corrosion attack exposes WC grains, resulting in a noticeable increase of wear rates. Accordingly, several studies have been focused on studying the synergic effects between erosion/abrasion and corrosion on the wear rates of cemented carbides (e.g. Refs. [15-19]). Cemented carbides exhibit brittle fracture behaviour related to the propagation of pre-existing flaws which may be processing-, shaping- or service- induced defects (e.g. Refs. $[2,8,20-24])$. Therefore, corrosion damage may also induce a detrimental effect on the strength and fatigue resistance of hardmetals due to the formation of corrosion pits with pronounced stress rising effects [8,9,25-27]. Thus, localized corrosion damage may have a critical role as a critical flaw, promoting a premature and un-expected failure $[8,9,25,27]$. However, to the best knowledge of the authors, 
only two studies have been addressed to correlate strength reduction and corrosion damage in cemented carbides, and both of them point out relevant strength degradation due to the stress rising effects produced by localized corrosion damage [8,27]. Thus, from a structural integrity perspective, it is essential to understand the detrimental impact that corrosion damage may induce in the performance of cemented carbides components.

The combined use of Focused Ion Beam (FIB) and Field Emission Scanning Electron Microscopy (FESEM) has been proved as an extremely useful technique for characterizing microstructure $[28,29]$ and damage phenomena [19,27,28,30-32] in cemented carbides. Following the above ideas, the aim of this investigation is two-fold: (1) to provide a thorough characterization of corrosion damage in cemented carbides immersed in a mine water solution, and (2) to study the detrimental effects of corrosion as a degrading factor of their mechanical performance. Within this purpose, the corrosion behaviour of five WC-Co cemented carbide grades having different microstructural characteristics was first investigated by means of electrochemical measurements. Then, retained strength after the inducement of corrosion damage was assessed and a corresponding fractographic analysis was conducted. Finally, a detailed characterization of corrosion damage-microstructure interactions in cemented carbides was done from tomographic reconstructions obtained by means of 3D FIB/FESEM serial sectioning and imaging.

\section{Materials and experimental aspects}

Carbide mean grain size $\left(d_{W C}\right)$ and the binder content $\left(\%_{\mathrm{wt}}\right)$ are the principal parameters involved in the definition of the microstructural assemblage of WC-Co hardmetals. Thus, in order to investigate the influence of the microstructure on the corrosion damage of cemented carbides, five experimental WC-Co hardmetal grades having different combinations of binder content and mean grain size were studied. All materials were supplied by Sandvik Hyperion. Main microstructural characteristics, including specimen designations, binder content, carbide mean grain size, contiguity $\left(C_{W C}\right)$ and binder mean free path $\left(\lambda_{C o}\right)$ are detailed in Table 1. Mean grain size was measured following the linear intercept method, using FESEM micrographs. On the other hand, carbide contiguity and binder mean free path were deduced following empirical relationships given in the literature [2,33]. A small amount of $\mathrm{Cr}_{3} \mathrm{C}_{2}$ (i.e. around a $5 \%$ wt of the binder content) was added to the composition of $11 \mathrm{M}, 15 \mathrm{UF}, 10 \mathrm{UF}$ and $3 \mathrm{UF}$ grades as a grain growth inhibitor.

Corrosion behaviour was first studied on the basis of electrochemical response of the grades under consideration. Corrosive media consisted on synthetic mine water $(\mathrm{SMW})$ solution $(\mathrm{pH}=6.3)$ containing dissolved salts whose composition is detailed in Table 2 [12,34]. The potentiodynamic polarisation technique was applied to study the corrosion resistance of the investigated cemented carbides in the aerated SMW solution at room temperature. The electrochemical tests were carried out using a standard three electrode system in which the test specimen was the working electrode, a plat-

Table 1

Nomenclature and microstructural parameters for investigated cemented carbides. *Presence of $\mathrm{Cr}_{3} \mathrm{C}_{2}$ in the composition as a grain growth inhibitor.

\begin{tabular}{lllll}
\hline Specimen code & Binder content $\left(\%_{\mathrm{wt}}\right)$ & $d_{W C}(\mu \mathrm{m})$ & $C_{W C}$ & $\lambda_{\text {binder }}(\mu \mathrm{m})$ \\
\hline $15 \mathrm{M}$ & 15 & $1.15 \pm 0.92$ & $0.30 \pm 0.07$ & $0.55 \pm 0.46$ \\
$11 \mathrm{M}^{*}$ & 11 & $1.12 \pm 0.71$ & $0.38 \pm 0.07$ & $0.42 \pm 0.28$ \\
$15 \mathrm{UF}^{*}$ & 15 & $0.47 \pm 0.22$ & $0.36 \pm 0.02$ & $0.24 \pm 0.11$ \\
$10 \mathrm{UF}^{*}$ & 10 & $0.39 \pm 0.19$ & $0.46 \pm 0.06$ & $0.16 \pm 0.06$ \\
$3 \mathrm{UF}^{*}$ & 3 & $0.37 \pm 0.09$ & $0.59 \pm 0.12$ & $0.08 \pm 0.03$ \\
\hline
\end{tabular}

Table 2

Synthetic mine water solution composition [12].

\begin{tabular}{ll}
\hline Compound & Concentration $(\mathrm{mg} / \mathrm{L})$ \\
\hline $\mathrm{CaCl} 2$ & 1058 \\
$\mathrm{Na} 2 \mathrm{SO} 4$ & 1237 \\
$\mathrm{MgSO} 4$ & 199 \\
$\mathrm{NaCl}$ & 1380 \\
\hline
\end{tabular}

inum plate was the counter electrode and a silver/silver chloride electrode was used as the reference electrode. After immersion in the electrolyte, the open circuit potential was stabilized during $30 \mathrm{~min}$. Subsequently, the sample was polarized into the cathodic region at $-500 \mathrm{mV}$. Then, the potential was increased towards the anodic region with a scan rate of $600 \mathrm{mV} / \mathrm{h}$ in the positive direction up to $500 \mathrm{mV}$.

Different levels of corrosion damage were induced through simple immersion of specimens in the stirred synthetic mine water corrosive media. Weight loss was measured after immersion tests performed from 24 to $360 \mathrm{~h}$. Before and after immersion tests, the specimens were first hand-cleaned by using soapy water and then ultrasonically cleaned for $15 \mathrm{~min}$ in ethanol, subsequently dried with a pure air, and weighted in an electronic balance having a resolution of $\pm 0.1 \mathrm{mg}$. Corrosion rates were estimated using the following equation:

$$
\text { Corrosion rate }(\mathrm{mm} / \text { year })=87.6\left(\frac{w}{A \rho t}\right)
$$

where $w$ is the weight loss in $\mathrm{mg} ; A$ is the surface area of the specimen in $\mathrm{cm}^{2} ; \rho$ is the density of the material in $\mathrm{g} / \mathrm{cm}^{3}$; and $t$ is the corrosion time in hours.

After immersion tests, retained flexural strength $\left(\sigma_{r}\right)$ was assessed. At least three samples were tested per investigated material and corrosion time. Flexural strength was determined by subjecting $4 \mathrm{~mm} \times 3 \mathrm{~mm} \times 45 \mathrm{~mm}$ specimens to failure using a four-point bending fully articulated test jig with inner and outer spans of 20 and $40 \mathrm{~mm}$, respectively. Subsequently, a detailed FESEM fractographic inspection was conducted with the purpose of characterizing corrosion damage as well as to discern critical failure sites. Strength data was also assessed for non-corroded specimens (reference) and at least 15 samples were tested per studied grade. Here, the surface which was later subjected to the maximum tensile load was polished to mirror-like finish and the edges were chamfered to reduce their effect as stress raisers. Besides fracture strength, each grade was mechanically characterized in terms of hardness and fracture toughness. Hardness (HV30) was measured using a Vickers indenter and applying a load of $294 \mathrm{~N}$. Fracture toughness $\left(K_{I c}\right)$ was determined using $5 \mathrm{~mm} \times 10 \mathrm{~mm} \times 45 \mathrm{~mm}$ single edge pre-cracked beam (SEPB) specimens and details on the procedure may be found elsewhere [35]. In this case, five samples were tested per material.

One of the main goals of this investigation is to conduct a detailed characterization of corrosion damage in cemented carbides by performing a $3 \mathrm{D}$ reconstruction of corrosion damage-microstructure interactions. In doing so, the serial sectioning and imaging technique was implemented in a FIB/FESEM (Zeiss Neon 40) equipment. Two samples were selected for the tomographic reconstruction, corresponding to the $15 \mathrm{M}$ grade immersed in the SMW solution for 7 and 15 days. Initially, an inspection of the corroded surface was carried out in order to select a small area of interest (of about $12 \mu \mathrm{m} \times 12 \mu \mathrm{m}$ ) for the reconstruction (e.g. Fig. 1). Before ion milling, a thin protective platinum layer was deposited on the area of interest. Then, a U-shaped trench with one cross-sectional surface 


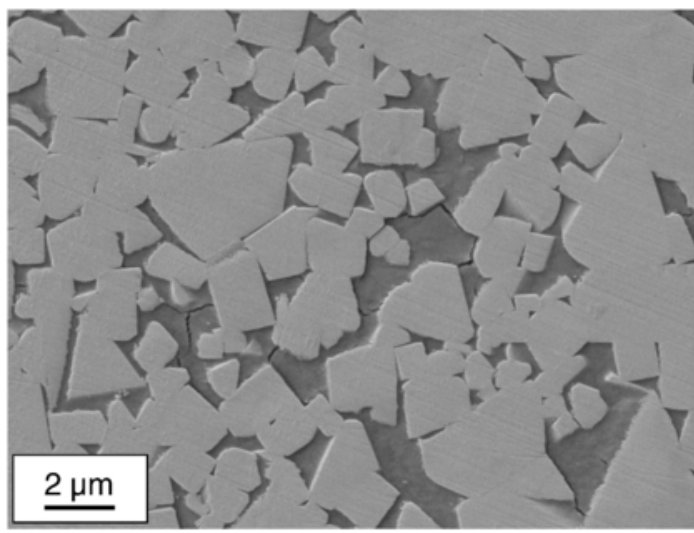

Fig. 1. FESEM micrograph corresponding to the selected region of interest for 3D reconstruction on the $15 \mathrm{M}$ hardmetal corroded for 7 days.

(perpendicular to specimen surface) was produced by FIB (Fig. 2). Subsequently, a series of micrographs were obtained by periodic removal of the material by FIB, within the U-shaped crater parallel to the cross-sectional surface. An example of obtained micrographs is shown for both, 7 and 15 days, in Fig. 3. A total volume of about $12 \mu \mathrm{m} \times 12 \mu \mathrm{m} \times 10 \mu \mathrm{m}$ was ion milled and around 600 images were obtained with a span of about $20 \mathrm{~nm}$ between them. The 3D reconstruction of the images was carried out using the commercial Avizo software. Obtained micrographs were aligned and a series of image processing techniques were implemented in order to correct, equalize, and differentiate the grey levels associated with each phase (WC, cobalt, corroded cobalt and microcrack-like leached out region). The next step consisted of segmenting these phases to finally reconstruct the $3 \mathrm{D}$ volume.
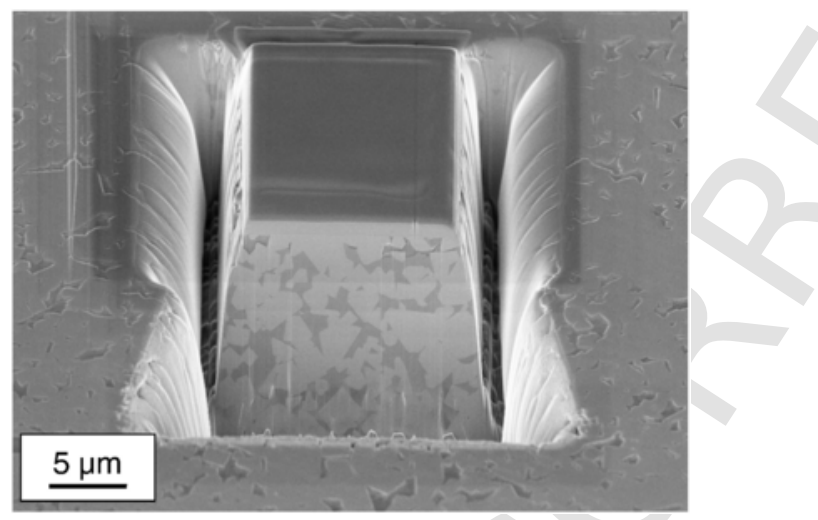

Fig. 2. FESEM image of the trench generated by FIB, previous to sequential milling around the region of interest for the $15 \mathrm{M}$ hardmetal corroded for 7 days.

\section{Results \& discussion}

\subsection{Corrosion behaviour}

The measured corrosion rates for the studied materials are shown in Fig. 4. It can be observed that the investigated $15 \mathrm{M}$ hardmetal grade exhibit much higher corrosion rates than the other studied materials. Indeed, during sintering chromium dissolves into the binder and that result in a beneficial effect against corrosion [36,37]. TEM analysis performed by Suttihiruangwong et al. demonstrated the formation of a passivating Co-based chromium oxide layer film at the binder surface which strongly decreased the rate of dissolution of the binder, and hence the improved corrosion resistance of Cr-containing cemented carbides [37]. On the other hand, the other materials showed similar corrosion rates. A small decrease of corrosion rates with grain size was evidenced when comparing $11 \mathrm{M}$ and $10 \mathrm{UF}$ grades. Contradictory results may be found in literature regarding the effect of grain size on the corrosion resistance of hardmetals [12,36]. On one hand Human and Exner [12] documented, on the basis of electrochemical measurements, that the WC mean size does not have a significant effect on the corrosion rates of cemented carbides. On the other hand, Tomlinson and Ayerst pointed out an increase of corrosion rates with grain size [36]. As discussed below, this slightly decrease in corrosion rates observed for the ultrafine grades may be related to the pseudopassive behaviour evidenced for these materials. As expected, a decrease of the corrosion rates when reducing the binder content was also evidenced. This decrease is related to a lower binder surface area exposed to the corrosive media, even though the reduction of the metallic phase surface area enhances the galvanic couple effect between WC and Co phases [13].

The electrochemical parameters measured for the studied cemented carbides are listed in Table 3. They include corrosion potential $\left(E_{\text {corr }}\right)$, corrosion current density $\left(i_{\text {corr }}\right)$, critical current density $\left(i_{c}\right)$ and minimum current density in pseudopassive region $\left(i_{p p}\right)$. As an example, the potentiodynamic polarisation curves obtained for the $15 \mathrm{M}$ and $15 \mathrm{UF}$ grades are shown in Fig. 5. It can be observed that the presence of chromium in the binder leads to lower values of the corrosion current density, as evidenced when comparing $11 \mathrm{M}$ and $15 \mathrm{M}$ grades [38]. Very interesting, pseudopassivation phenomenon was only discerned for the ultrafine grades. This is particularly clear in Fig. 5, where a continuous anodic dissolution is observed for the $15 \mathrm{M}$ hardmetal, while the current density for the 15UF grade drops to lower values after achieving the critical current density. In agreement with previous results [39], pseudopassivation phenomenon is a consequence of a limitation of the cobalt diffusion that causes a decrease of the current flow. After the dissolution of the cobalt present at the surface, the current flow is limited because cobalt has to diffuse throughout the remaining porous tungsten carbide skeleton. Thus, when the binder mean free path gets shorter, as it is the case for the
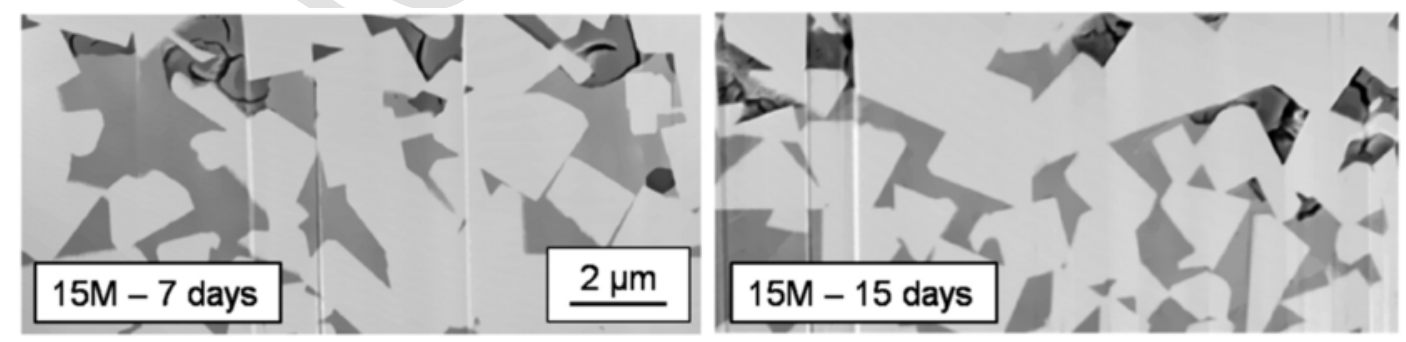

Fig. 3. Micrographs showing corrosion damage-microstructure interactions on serial sections obtained by means of FIB/FESEM after being filtered. 


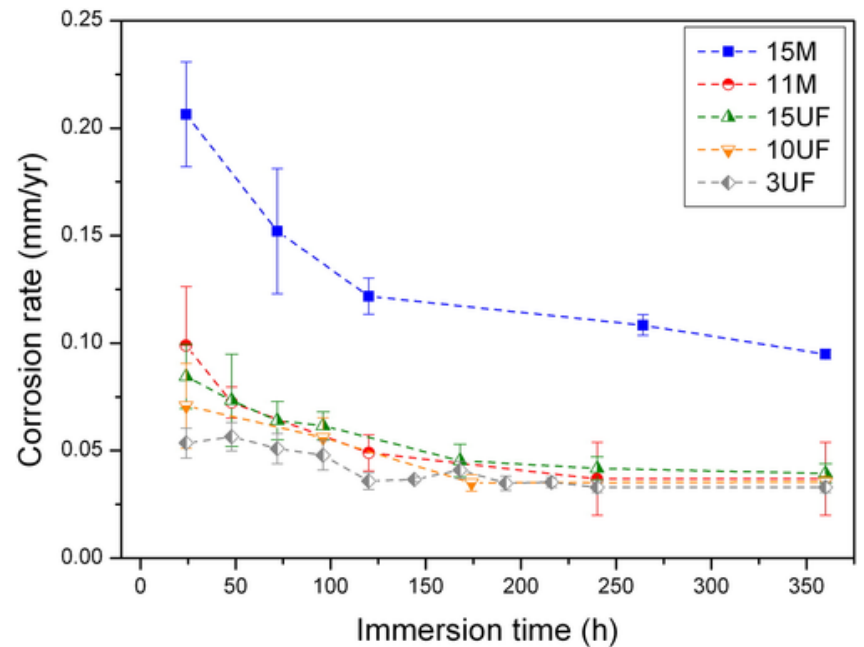

Fig. 4. Corrosion rates as a function of immersion time for the studied cemented carbides.

Table 3

Electrochemical parameters of the studied cemented carbides. They include corrosion potential $\left(E_{\text {corr }}\right)$, corrosion current density $\left(i_{c o r r}\right)$, critical current density $\left(i_{c}\right)$ and minimum current density in pseudopassive region $\left(i_{p p}\right)$.

\begin{tabular}{lllll}
\hline Specimen code & $E_{\text {corr }}(\mathrm{mV})$ & $i_{\text {corr }}\left(\mu \mathrm{A} / \mathrm{cm}^{2}\right)$ & $i_{c}\left(\mathrm{~mA} / \mathrm{cm}^{2}\right)$ & $i_{p p}\left(\mathrm{~mA} / \mathrm{cm}^{2}\right)$ \\
\hline $15 \mathrm{M}$ & -287 & 6.23 & 3.72 & - \\
$11 \mathrm{M}$ & -291 & 2.87 & 3.51 & - \\
$15 \mathrm{UF}$ & -274 & 3.64 & 0.56 & 0.23 \\
$10 \mathrm{UF}$ & -264 & 2.41 & 0.40 & 0.18 \\
3UF & -268 & 1.13 & 0.51 & 0.16 \\
\hline
\end{tabular}

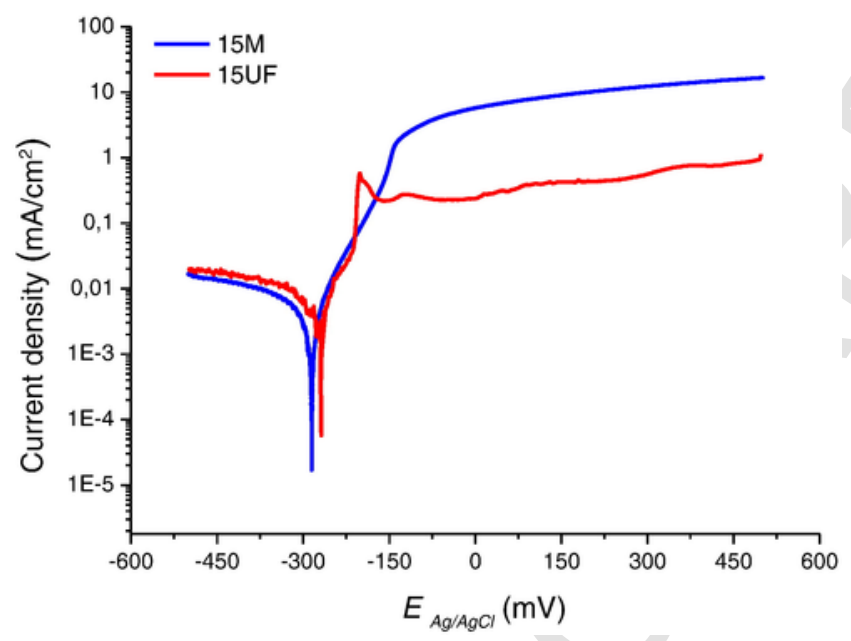

Fig. 5. Potentiodynamic polarisation of $15 \mathrm{M}$ and $15 \mathrm{UF}$ alloys in synthetic mine water.

ultrafine grades, cobalt diffusion gets lessened. On the other hand, $15 \mathrm{M}$ did not show a pseudopassivation phenomenon. In addition, it is interesting to notice that ultrafine grades exhibit less negative $E_{\text {corr }}$, i.e. more noble values, than medium ones for similar binder contents (see Table 3), which yields lower corrosion current densities.

\subsection{Residual strength of corroded hardmetals}

The mechanical characterization of investigated materials prior to immersion tests includes the assessment of their hardness, fracture toughness, flexural strength and Weibull modulus. Obtained results are listed in Table 4. As expected, hardness rises and fracture toughness decreases when the binder mean free path gets shorter [2]. Tougher grades exhibited extremely high Weibull modulus values, whereas higher strength scatters were measured for harder hardmetals.

Retained strength after corrosion is plotted as a function of immersion time in Fig. 6a. Same experimental data is given in Fig. 6b as normalized strength loss, using as reference baseline the strength exhibited by non-corroded specimens. These results clearly indicate

Table 4

Hardness, fracture toughness, flexural strength and Weibull modulus for the investigated cemented carbides.

\begin{tabular}{lllll}
\hline $\begin{array}{l}\text { Specimen } \\
\text { code }\end{array}$ & $\begin{array}{l}H V 30 \\
(\mathrm{GPa})\end{array}$ & $\begin{array}{l}K_{I c} \\
\left(\mathrm{MPa} \cdot \mathrm{m}^{1 / 2}\right)\end{array}$ & $\begin{array}{l}\text { Flexural strength } \\
(\mathrm{MPa})\end{array}$ & $\begin{array}{l}\text { Weibull } \\
\text { modulus }\end{array}$ \\
\hline $15 \mathrm{M}$ & $11.2 \pm 0.1$ & $15.2 \pm 0.4$ & $2912 \pm 88$ & 39 \\
$11 \mathrm{M}$ & $12.8 \pm 0.2$ & $13.9 \pm 0.3$ & $3101 \pm 102$ & 36 \\
$15 \mathrm{UF}$ & $13.2 \pm 0.1$ & $11.3 \pm 0.6$ & $3869 \pm 109$ & 42 \\
$10 \mathrm{UF}$ & $15.7 \pm 0.6$ & $10.4 \pm 0.3$ & $3422 \pm 512$ & 11 \\
$3 \mathrm{UF}$ & $18.9 \pm 0.8$ & $7.4 \pm 0.7$ & $2214 \pm 313$ & 8 \\
\hline
\end{tabular}

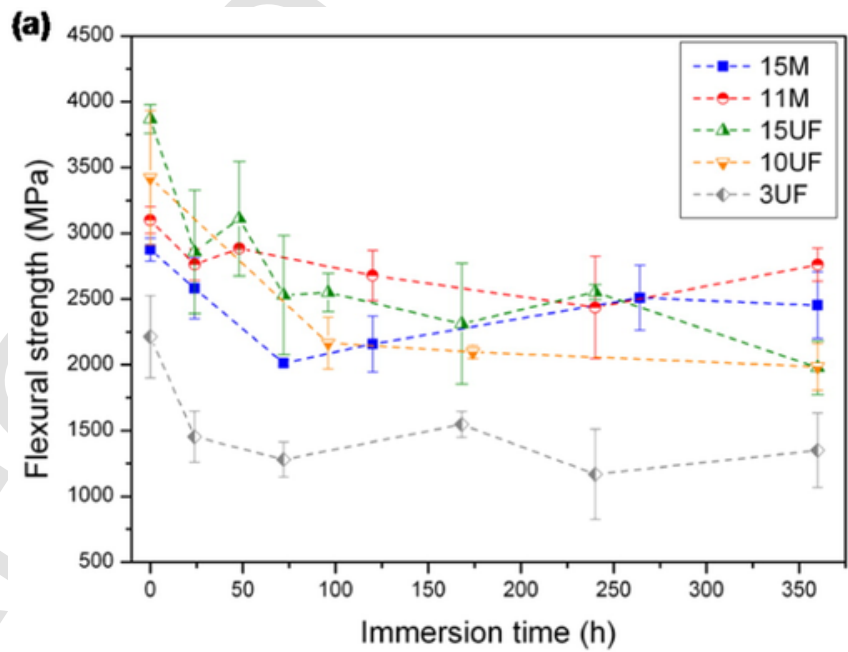

(b)

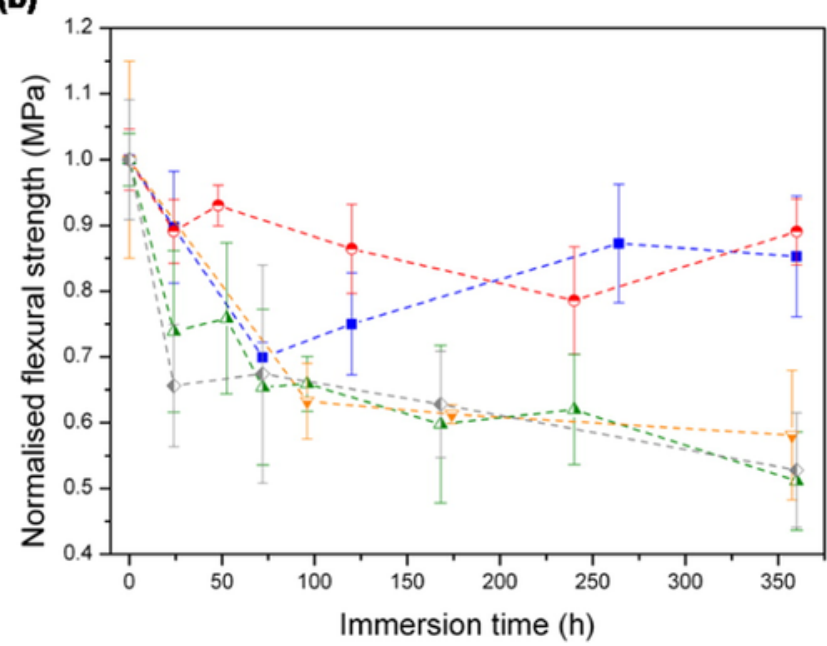

Fig. 6. (a) Retained strength and (b) normalized retained strength as a function of corrosion time in the stirred corrosive media for the materials here studied. Strength of non-corroded specimens is used as reference baseline. 
that; (1) corrosion may produce a relevant strength degradation in cemented carbides that is highly dependent on their microstructure; (2) relative changes of strength loss are pronounced for short exposure times, but tend to stabilize for longer immersion times; and (3) retained strength results are characterized by a high dispersion probably related to significant differences in the size and geometry of corrosion damage acting as a critical flaws for fracture. Attempting to document and analyse corrosion-induced damage promoting failure, a detailed inspection of fractured surfaces was conducted by means of FESEM. In doing so, critical flaws were identified and documented. Fractographic examination reveals that corrosion pits act as critical points for starting fracture. A strong effect of the carbide mean grain size on the size and shape of these pits, and accordingly on strength degradation was evidenced. On one hand, medium-sized hardmetals exhibit semi-elliptical corrosion pits. On the other hand, corrosion in ultrafine grades is characterized by a heterogeneous surface layer, where localized sharp corrosion pits form at the corrosion front. In this sense, after the dissolution of the cobalt directly exposed to the media, the oxidation for ultrafine grades continues within the pit itself. The pits downward growth evidenced for ultrafine grades is speculated to be related to several interacting factors: shorter path between centre of binder pools and carbide/binder interface together with higher surface area of interfaces as grain size decreases, gravity effects and a synergic increase of [Cl-] concentration at sharper tips of angular corrosion pits as they grow. Consequently, the formation of such defects could induce a decrease in service life due to their effect as stress concentrators for crack initiation and growth. Some examples are shown in Fig. 7, corresponding to short and long immersion times, for the investigated $15 \mathrm{UF}, 15 \mathrm{M}$ and $11 \mathrm{M}$ hardmetals.

Concerning microstructural effects on strength degradation, the ultrafine-sized studied grades are much more affected by corrosion damage than medium-sized ones. Indeed, they exhibit strength losses of about a $30 \%$ after immersion time of 3 days, increasing up to values close to a $50 \%$ for longer exposure times. Critical corrosion damage is characterized by a selective attack of the metallic binder that leaves a WC skeleton surface layer $[12,13,39,40]$. Fractographic examination reveals that for the ultrafine grades, the depth of the corrosion front increases as immersion time into the corrosive media gets longer. Nonetheless, the corrosion front is not homogeneous and localized corrosion pits at the interface between the corrosion front and the un-corroded surface were discerned. Clear examples of such phenomena are given in Fig. 7. The formation of these corrosion features is of crucial importance for determining effective strength degradation, as they act as preferential sites for crack nucleation and
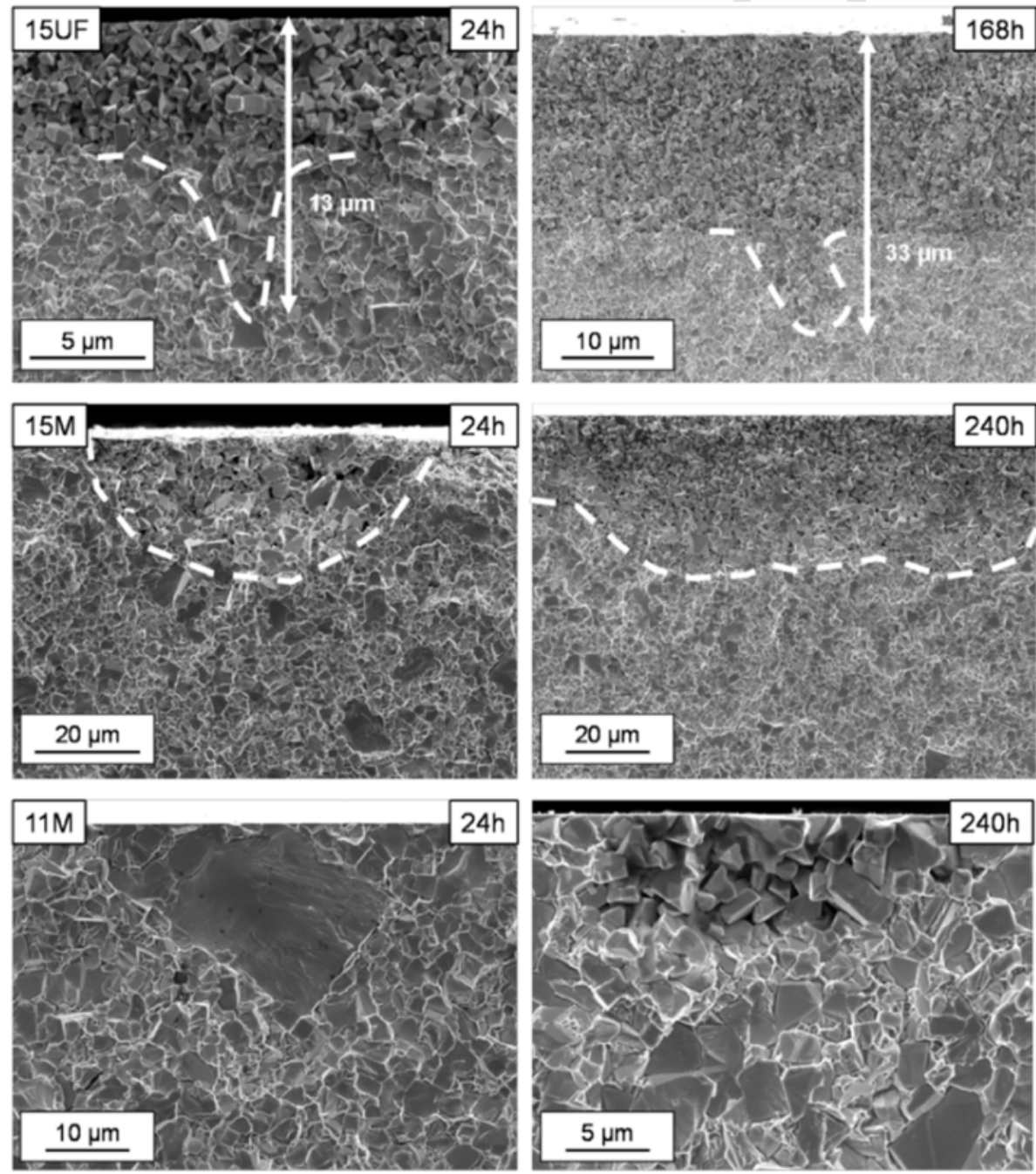

Fig. 7. Critical corrosion damage promoting failure for different corrosion times the $15 \mathrm{UF}, 15 \mathrm{M}$ and $11 \mathrm{M}$ WC-Co cemented carbides. 
extension [8]. However, as immersion time increases, the ratio between the pit depth and the thickness of the damaged layer decreases. As a consequence, the stress concentration role played by corrosion pits gets geometrically lessened. This fact explains the lower relative changes observed in retained strength for long exposure times.

Corrosion damage is less critical for the $15 \mathrm{M}$ investigated grade and its strength is retained up to $80 \%$ level for long immersion times. Two aspects should be considered for explaining the differences found between $15 \mathrm{UF}$ and $15 \mathrm{M}$ specimens. First, for similar binder content, the medium-sized grade is tougher, and thus a higher damage-tolerance level is to be expected $[24,41,42]$. Hence, as binder mean free path increases, and likewise fracture toughness, damage mode shifts from fracture to deformation controlled, increasing the tolerance to presence of critical damage [24]. Second, the geometry of corrosion induced critical damage is significantly different for both materials, as it is clearly evidenced in Fig. 7. In the case of the 15M hardmetal, critical corrosion damage consists of surface semi-elliptical corrosion pits. The depth of these pits slowly growths as immersion time increases. However, this is not the case for their length, which increases with corrosion time. Thus, as exposure time gets longer, the ellipse eccentricity of corrosion induced pits increases. It should be noted that this fact relates to the stabilization of the residual strength of the $15 \mathrm{M}$ grade for long immersion times. In agreement with previous experiments carried out in acidic solutions, binder surface area distribution plays a decisive role on the corrosion behaviour of cemented carbides [39]. For hardmetals with large binder mean free paths corrosion develops homogenously at the surface. On the other hand, corrosion becomes localized when the exposed area to corrosive media is reduced (i.e. ultrafine cemented carbides).

The strength of the $11 \mathrm{M}$ grade is barely reduced due to corrosion damage. In fact, identified critical flaws for short exposure times were mainly not corrosion-related, but rather pre-existing flaws in- herent to the manufacturing process (Fig. 7). Therefore, in such cases corrosion pits were less critical than pre-existing manufacturing defects and the strength was evidently retained. For longer corrosion times, semi-elliptical corrosion flaws were discerned (Fig. 7). Thus, it could be concluded that $11 \mathrm{M}$ hardmetal exhibits the best compromise between corrosion resistance and damage tolerance.

\subsection{D FIB/FESEM characterization of corrosion-induced damage}

A detailed characterization of corrosion damage was conducted by means of the FESEM/FIB technique for the $15 \mathrm{M}$ hardmetal after being immersed for $7(168 \mathrm{~h})$ and $15(360 \mathrm{~h})$ days in the corrosive medium. Examples of obtained micrographs after the application of image processing techniques showing corrosion damage-microstructure interactions are shown in Fig. 3 for both investigated conditions. In Fig. 8 such phases were segmented and appear as yellow (WC carbides), blue (cobalt), green (corroded cobalt) and red (microcrack-like void). The whole $3 \mathrm{D}$ reconstructed volume for both analysed conditions is shown in Fig. 9. In addition, an illustrative Video detailing the 3D FIB/FESEM reconstruction, segmentation and analysis process is provided. To access to the Video component, simply click the image visible below (online version only). From the observation of these figures and the provided Video, corrosion damage may be described by a selective attack of the metallic binder. Thus, the Co binder follows an anodic oxidation reaction and is dissolved in the corrosive solution $[12,13,39,40]$. That leads to effective leaching of the metallic phase; and thus, the apparition of microcrack-like voids. Although the physico-chemical mechanisms behind origin and evolution of these microflaws is unclear (out of the scope of this study), they are probably related to weak locations associated with boundaries between corroded and uncorroded regions within the binder. Very interesting, they are mainly located at the binder pools

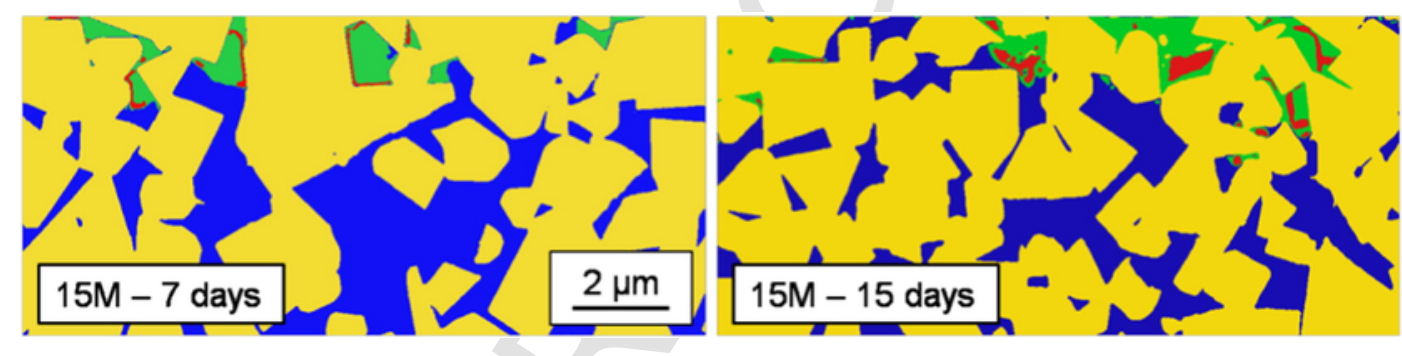

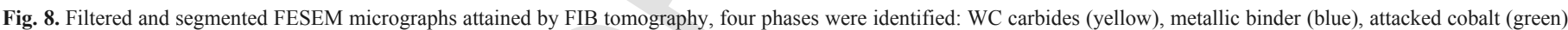
and microcrack-like voids (red). (For interpretation of the references to color in this figure legend, the reader is referred to the web version of this article.)

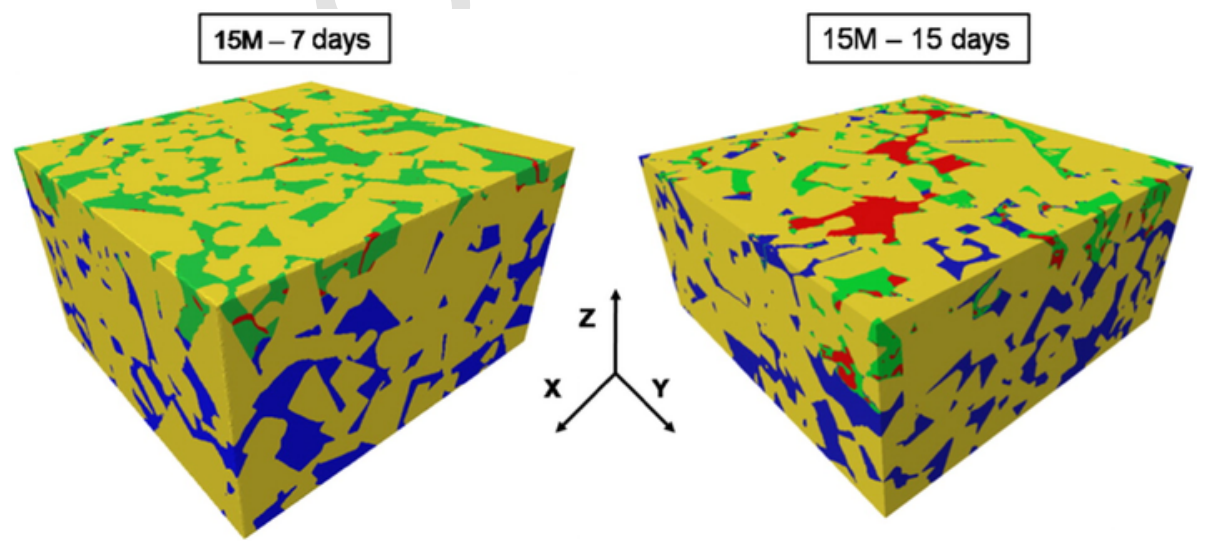

Fig. 9. 3D reconstructed image describing corrosion damage-microstructure interactions for the $15 \mathrm{M}$ hardmetal here studied (after 7 and 15 days of exposure time). 
centres (Fig. 3). As immersion time increases, corrosion damage evolves to extensive binder leaching and corrosion products formation, resulting then in unsupported carbide grains throughout the affected surface.

From the observation of obtained micrographs, and according to previous investigations (e.g. Ref. [13,40]), it is evident that the binder phase controls the corrosion behaviour of WC-Co composites. It is therefore reasonable to assume the binder itself, the corroded binder and the microflaw (weak location) 'phases' as the pertinent features for describing corrosion damage-microstructure interactions in hardmetals. With this purpose, a study of the relative distribution and interconnectivity degree of those phases was attempted by means of the image analysis technique of skeletonization. This process involves the simplification of the phase of interest by transforming it in filaments whose diameter and colour are related to its local size. In this study, local regions corresponding to large volumes occupied at the small length scale are characterized by thick ligaments coloured in red. Conversely, if presence of the phase at the local level becomes scarcer, cords become thinner and blue. This enables the assessment of certain distribution properties such as the interconnectivity degree and the length and local thickness of each phase. The skeleton of the binder, the corroded binder (i.e. corresponding to the addition of the attacked cobalt (green) and the microcrack-like void (red) phases), and of the corrosion-related microflawed phases is shown in Fig. 10. It reveals a long range and fully interconnected cobalt binder, whereas the microcracked-like phase forms short range and locally interconnected networks. Very interesting, these results indicate that the binder phase is composed by a single group (i.e. the cobalt phase is fully interconnected), validating the fact that $\mathrm{WC}$ and binder phases form two fully interconnected networks in the un-corroded cemented carbide. This perfectly interpenetrated structure is attributable to the very low interfacial energy, excellent wetting and very good adhesion for the WC and Co couple, and is the main reason for explaining the outstanding fracture toughness levels exhibited by cemented carbides $[42,43]$.

\section{Conclusions}

In this study the influence of microstructure on the tolerance to damage induced by corrosion in WC-Co cemented carbides has been investigated. Corrosion media used was an agitated mine water solution, and damage tolerance was assessed on the basis of the retained strength after corrosion exposure. The investigation also included a characterization of corrosion damage-microstructure interactions by means of the 3D FIB/FESEM technique. Based on obtained results, the following conclusions may be drawn:

1. Strong microstructural effects on the corrosion behaviour of cemented carbides when immersed in a synthetic mine water solution were evidenced. A pseudopassive behaviour was determined for ultrafine grades which slightly decreases corrosion rates due to a limitation of the diffusion of cobalt from the surface. Medium grain sized hardmetals do not exhibit this pseudopassive regime.

2. Corrosion damage may result in relevant strength degradation in cemented carbides. However, relative changes in residual strength become less pronounced with exposure time, as corrosion damage gets homogenized. Within this context, the microstructure plays a principal role in defining the effective tolerance to the induced damage level.

3. Strength loss associated with corrosion damage is rationalized on the basis of stress rising effects related to corrosion pits. Semi-elliptical and sharp angular corrosion pits were identified as critical corrosion damage for medium- and ultrafine-sized hardmetals, respectively. The latter have much more pronounced stress rising effects and consequently, ultrafine graded cemented carbides exhibit higher strength losses in the presence of corrosion damage.

4. 3D FIB/FESEM tomography reveals localized corrosion pits with variable and partial interconnectivity (as a function of depth). Corrosion damage is related to the selective dissolution of the Co binder. Initially, cobalt leaching is mainly located at centres of binder pools. However, as exposure time in the media increases,

\section{(a)}
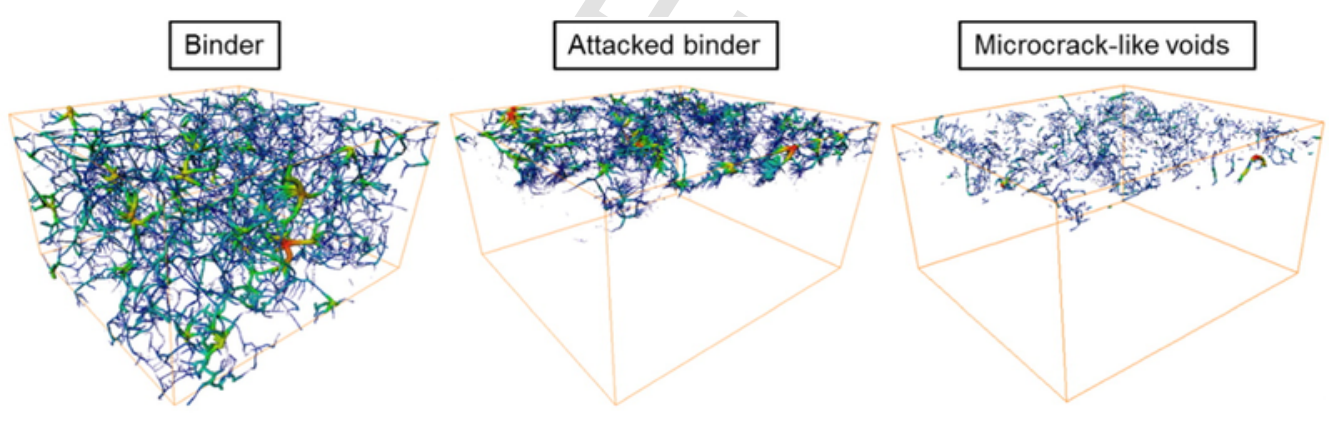

(b)
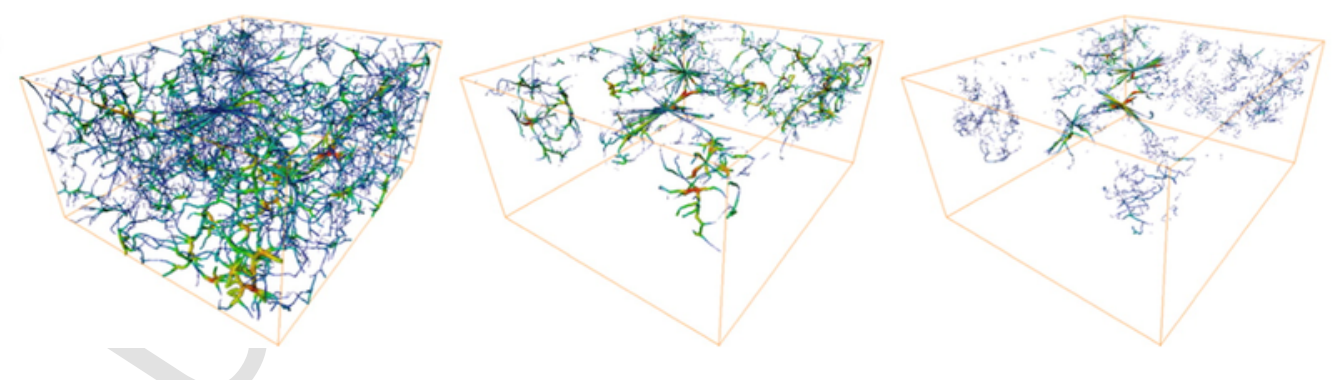

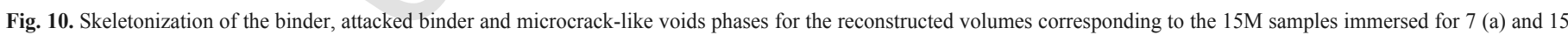
(b) days. 
corrosion evolves consuming the rest of the binder pools which finally leaves a WC skeleton.

Supplementary data to this article can be found online at http://dx. doi.org/10.1016/j.matdes.2016.08.066.

\section{Acknowledgements}

This work was financially supported by the Spanish Ministerio de Economía y Competitividad (Grants MAT2012-34602 and MAT2015-70780-C4-3-P). Additionally, J.M. Tarragó acknowledges the Ph.D. scholarship received from the collaborative Industry-University program between Sandvik Hyperion and Universitat Politècnica de Catalunya.

\section{References}

[1] H.E. Exner, Physical and chemical nature of cemented carbides, Int. Met. Rev. 24 (1979) 149-173.

[2] B. Roebuck, E.A. Almond, Deformation and fracture processes and the physical metallurgy of WC-Co hardmetals, Int. Mater. Rev. 33 (1988) 90-110.

[3] G.S. Upadhyaya, Materials science of cemented carbides - an overview, Mater. Des. 22 (2001) 483-489.

[4] G.S. Upadhyaya, Cemented Tungsten Carbides: Production, Properties, and Testing, Noyes Publications, New Jersey, USA, 1998.

[5] L. Prakash, Fundamentals and general applications of hardmetals, in: V.K. Sarin, D. Mari, L. Llanes (Eds.), Compr. Hard Mater, Elsevier, UK, 2014, pp. 29-90.

[6] V.A. Tracey, Nickel in hardmetals, Int. J. Refract. Met. Hard Mater. 11 (1992) $137-149$.

[7] U. Beste, T. Hartzell, H. Engqvist, N. Axén, Surface damage on cemented carbide rock-drill buttons, Wear 249 (2001) 324-329.

[8] V.A. Pugsley, G. Korn, S. Luyckx, H.G. Sockel, W. Heinrich, M. Wolf, H Feld, R. Schulte, The influence of a corrosive wood-cutting environment on the mechanical properties of hardmetal tools, Int. J. Refract. Met. Hard Mater. 19 (2001) 311-318.

[9] V.A. Pugsley, H.-G. Sockel, Corrosion fatigue of cemented carbide cutting tool materials, Mater. Sci. Eng. A 366 (2004) 87-95.

[10] R. Lu, L. Minarro, Y.-Y. Su, R.M. Shemenski, Failure mechanism of cemented tungsten carbide dies in wet drawing process of steel cord filament, Int. J. Refract. Met. Hard Mater. 26 (2008) 589-600.

[11] W.J. Tomlinson, C.R. Linzell, Anodic polarisation and corrosion of cemented carbides with cobalt and nickel binders, J. Mater. Sci. 23 (1988) 914-918.

[12] A.M.M. Human, H.E. Exner, The relationship between electrochemical behaviour and in-service corrosion of WC based cemented carbides, Int. J. Refract. Met. Hard Mater. 15 (1997) 65-71.

[13] S. Hochstrasser, Y. Mueller, C. Latkoczy, S. Virtanen, P. Schmutz, Analytical characterization of the corrosion mechanisms of WC-Co by electrochemical methods and inductively coupled plasma mass spectroscopy, Corros. Sci. 49 (2007) 2002-2020

[14] D.S. Konadu, J. van der Merwe, J.H. Potgieter, S. Potgieter-Vermaak, C.N. Machio, The corrosion behaviour of WC-VC-Co hardmetals in acidic media, Corros. Sci. 52, 2010, 3118-3125

[15] H. Engqvist, U. Beste, N. Axén, The influence of $\mathrm{pH}$ on sliding wear of WC-based materials, Int. J. Refract. Met. Hard Mater. 18 (2000) 103-109

[16] F.J.J. Kellner, H. Hildebrand, S. Virtanen, Effect of WC grain size on the corrosion behavior of WC-Co based hardmetals in alkaline solutions, Int. J. Refract. Met. Hard Mater. 27 (2009) 806-812.

[17] A.J. Gant, M.G. Gee, A.T. May, The evaluation of tribo-corrosion synergy for WC-Co hardmetals in low stress abrasion, Wear 256 (2004) 500-516.

[18] M.R. Thakare, J.A. Wharton, R.J.K. Wood, C. Menger, Exposure effects of alkaline drilling fluid on the microscale abrasion-corrosion of WC-based hardmetals, Wear 263 (2007) 125-136.

[19] A.J. Gant, M.G. Gee, D.D. Gohil, H.G. Jones, L.P. Orkney, Use of FIB/SEM to assess the tribo-corrosion of $\mathrm{WC} / \mathrm{Co}$ hardmetals in model single point abrasion experiments, Tribol. Int. 68 (2013) 56-66.

[20] P. Kenny, The application of fracture mechanics to cemented tungsten carbides, Powder Metall. 14 (1971) 22-38.
[21] H. Suzuki, K. Hayashi, The strength of WC-Co cemented carbide in relation to structural defects, Trans. Jpn. Inst. Metals 16 (1975) 353-360.

[22] B. Casas, X. Ramis, M. Anglada, J.M. Salla, L. Llanes, Oxidation-induced strength degradation of WC-Co hardmetals, Int. J. Refract. Met. Hard Mater. 19 (2001) 6-12.

[23] B. Casas, Y. Torres, L. Llanes, Fracture and fatigue behavior of electrical-discharge machined cemented carbides, Int. J. Refract. Met. Hard Mater. 24 (2006) $162-167$.

[24] A. Góez, D. Coureaux, A. Ingebrand, B. Reig, E. Tarrés, A. Mestra, A. Mateo, E. Jiménez-Piqué, L. Llanes, Contact damage and residual strength in hardmetals, Int. J. Refract. Met. Hard Mater. 30 (2012) 121-127.

[25] W.J. Tomlinson, I.D. Molyneux, Corrosion, erosion-corrosion, and the flexural strength of WC-Co hardmetals, J. Mater. Sci. 26 (1991) 1605-1608

[26] W.J. Przybylowicz, S.B. Luyckx, J.I.W. Watterson, Proton microprobe investigation of the causes of pitting in cemented tungsten carbide, Nucl. Instruments Met. Phys. Res. Sect. B Beam Interact. Mater. Atoms. 79 (1993) 428-431.

[27] J.M. Tarragó, G. Fargas, E. Jimenez-Piqué, A. Felip, L. Isern, D. Coureaux, J.J Roa, I. Al-Dawery, J. Fair, L. Llanes, Corrosion damage in WC-Co cemented carbides: residual strength assessment and 3D FIB-FESEM tomography characterisation, Powder Metall. 57 (2014) 324-330.

[28] K.P. Mingard, H.G. Jones, M.G. Gee, B. Roebuck, A. Gholinia, B. Winiarski, P. Withers, In: 3D Imaging of structures in bulk and surface modified WC-Co hardmetals, Proceedings Euro PM 2012, EPMA, Basel, 2012, pp. 155-160.

[29] I. Borgh, P. Hedström, J. Odqvist, A. Borgenstam, J. Ågren, A. Gholinia, B. Winiarski, P. Withers, G.E. Thompson, K.P. Mingard, M.G. Gee, On the three-dimensional structure of WC grains in cemented carbides, Acta Mater. 61 (2013) 4726-4733

[30] J.M. Cairney, P.R. Munroe, J.H. Schneibel, Examination of fracture surfaces using focused ion beam milling, Scr. Mater. 42 (2000) 473-478.

[31] U. Beste, E. Coronel, S. Jacobson, Wear induced material modifications of cemented carbide rock drill buttons, Int. J. Refract. Met. Hard Mater. 24 (2006) $168-176$.

[32] J.M. Tarragó, E. Jimenez-Piqué, M. Turón-Viñas, L. Rivero, I. Al-Dawery, L. Schneider, L. Llanes, Fracture and fatigue behavior of cemented carbides: 3D focused ion beam tomography of crack-microstructure interactions, Int. J. Powder Metall. 50 (2014) 1-10.

[33] J.M. Tarragó, D. Coureaux, Y. Torres, F. Wu, I. Al-Dawery, L. Llanes, Implementation of an effective time-saving two-stage methodology for microstructural characterization of cemented carbides, Int. J. Refract. Met. Hard Mater. 55 (2016) 80-86.

[34] C.N. Machio, D.S. Konadu, J.H. Potgieter, S. Potgieter-Vermaak, J. Van der Merwe, Corrosion of WC-VC-Co hardmetal in neutral chloride containing media, ISRN Corros. 2013 (2013) 506759.

[35] Y. Torres, D. Casellas, M. Anglada, L. Llanes, Fracture toughness evaluation of hardmetals: influence of testing procedure, Int. J. Refract. Met. Hard Mater. 19 (2001) 27-34

[36] W.J. Tomlinson, N.J. Ayerst, Anodic polarization and corrosion of WC-Co hardmetals containing small amounts of $\mathrm{Cr}_{3} \mathrm{C}_{2}$ and/or VC, J. Mater. Sci. 24 (1989) 2348-2352.

[37] S. Sutthiruangwong, G. Mori, R. Kösters, Passivity and pseudopassivity of cemented carbides, Int. J. Refract. Met. Hard Mater. 23 (2005) 129-136.

[38] G. Mori, H. Zitter, A. Lackner, M. Schretter, Influencing the corrosion resistance of cemented carbides by addition of $\mathrm{Cr}_{3} \mathrm{C}_{2}$, TiC and TaC, in: $\mathrm{G}$. Kneringer, P. Rödhammer, H. Wildner (Eds.), Proceedings of the 15 th international Plansee seminar, 2001, pp. 222-236.

[39] S. Sutthiruangwong, G. Mori, Corrosion properties of Co-based cemented carbides in acidic solutions, Int. J. Refract. Met. Hard Mater. 21 (2003) 135-145.

[40] S. Hochstrasser-Kurz, D. Reiss, T. Suter, C. Latkoczy, D. Günther, S. Virtanen, P.J. Uggowitzer, P. Schmutz, ICP-MS, SKPFM, XPS, and microcapillary investigation of the local corrosion mechanisms of WC-Co hardmetal, J. Electrochem. Soc. 155 (2008) 415-426.

[41] Y. Torres, R. Bermejo, F.J. Gotor, E. Chicardi, L. Llanes, Analysis on the mechanical strength of WC-Co cemented carbides under uniaxial and biaxial bending, Mater. Des. 55 (2014) 851-856.

[42] J.M. Tarragó, D. Coureaux, Y. Torres, D. Casellas, I. Al-Dawery, L. Schneider, L. Llanes, Microstructural effects on the R-curve behavior of WC-Co cemented carbides, Mater. Des. 97 (2016) 492-501.

[43] L.S. Sigl, H.E. Exner, Experimental study of the mechanics of fracture in WC-Co alloys, Metall. Trans. A. 18A (1987) 1299-1308. 